\title{
Características e Tendências da Pesquisa Empírica em Democracia Digital no Brasil: MÉTODOS, INSTRUMENTOS E ABORDAGENS ${ }^{1,2}$
}

Sivaldo Pereira da Silva ${ }^{3}$

\section{INTRODUÇÃO}

O objetivo deste estudo é produzir um levantamento do atual estágio de desenvolvimento da pesquisa sobre democracia digital com foco nos estudos de caráter prático e empírico. $\mathrm{O}$ intuito é trazer um panorama por meio de um estudo bibliométrico exploratório baseado em uma amostragem representativa, capaz de identificar que tipo de temas, metodologias, instrumentos de coleta e análise de dados vêm sendo utilizados, buscando assim contribuir para uma melhor compreensão dessa área.

Para abordar essas questóes, o trabalho está organizado em três partes, além desta introdução. Na seçáo 2 será realizada uma caracterização conceitual do que devemos compreender por democracia digital, seguida por uma síntese de estudos bibliométricos que buscam compreender esse campo em expansão. Na seção 3 serão expostos os resultados da pesquisa, trazendo um mapeamento dos principais indicadores nesse campo, com foco nos estudos empírico-metodológicos em periódicos brasileiros indexados. Na seção 4 são apresentadas as consideraçóes finais.

\section{DEMOCRACIA DIGITAL: O DESENVOLVIMENTO DE UM CAMPO E PRECEDENTES BIBLIOMÉTRICOS}

A expressão democracia digital (Digital democracy) emerge na esteira das inovaçóes tecnológicas e políticas do final do século XX e se apresenta com duas faces simultâneas: i) trata-se de um campo de estudo, que vem se consolidando como uma área multidisciplinar; e ii) refere-se a um campo prático, que vem se alicerçando na forma de política pública, design institucional e também em experimentos civis. Trata-se da democracia que conhecemos sendo permeada por tecnologias digitais que são utilizadas em práticas e processos políticos. Naturalmente, embora o foco de estudos democráticos tenha um pano de fundo normativo que a própria ideia de democracia pressupóe, isso também incorpora os estudos acerca dos problemas, riscos, empecilhos e desafios que a prática, o sistema e os regimes democráticos enfrentam diante das inovaçóes tecnológicas do ambiente digital. Além disso, como ilustram Silva, Sampaio e Bragatto (2016), a melhor metáfora para se compreender a concepção de democracia digital é observar que se trata de uma expressão ao redor da qual se "orbitam" sub-temas como participação política on-line, deliberação pública, transparência, dados abertos, ativismo on-line, campanhas eleitorais via internet, parlamento digital etc.

Por se tratar de um campo relativamente novo, algumas pesquisas bibliométricas começaram a surgir recentemente no Brasil. Curtinovi e Parmeggiani (2015) produziram um dos primeiros levantamentos sobre pesquisa em democracia digital, especificamente com foco na produção acadêmica de dissertaçóes

1. DOl: http://dx.doi.org/10.38116/bapi25art1

2. Este artigo é uma síntese de Texto para Discussão a ser publicado, realizado no âmbito do projeto Democracia Digital: Mapeando o Debate e Articulando Experiências Nacionais e Internacionais.

3. Pesquisador do Programa de Pesquisa para o Desenvolvimento Nacional (PNPD) na Diretoria de Estudos e Políticas do Estado, das Instituições e da Democracia (Diest) do Ipea; professor da Faculdade de Comunicação (FAC) e do Programa de Pós-Graduação em Comunicação (PPG-FAC) da Universidade de Brasília (UnB); coordenador do Centro de Estudos em Comunicação, Tecnologia e Política (CTPol-UnB). 
e teses defendidas entre 1990 a 2013. A pesquisa apontou que $47 \%$ dos trabalhos eram provenientes de programas de pós-graduação em comunicação; $18 \%$ de administração e $18 \%$ de ciência política - outras áreas, como ciências sociais, ciência da informação e políticas públicas aparecem com $5 \%$ ou menos. O estudo também identificou que três universidades, juntas, foram responsáveis pela metade dos trabalhos acadêmicos defendidos. São elas: Universidade Federal da Bahia (UFBA), Universidade de Brasília (UnB) e Universidade Federal do Rio Grande do Sul (UFRGS).

Com foco na administração, Pinho et al. (2019) publicaram uma análise sobre democracia digital baseados em um corpus de 49 artigos coletados de periódicos científicos brasileiros. O estudo identificou que o volume de publicaçóes cresceu principalmente a partir de 2011, tendo um aumento significativo em 2016, apesar de uma queda em 2014, que quebrou a trajetória crescente. Esse conjunto de trabalhos estava concentrado principalmente em sete periódicos da área, com autores principalmente de seis instituiçóes: Fundação Getulio Vargas (FGV), Universidade Federal de Santa Catarina (UFSC), Pontifícia Universidade Católica do Paraná (PUC-PR), Universidade de São Paulo (USP), UFBA e UnB.

Com escopo mais amplo, Freitas et al. (2018) apresentaram no congresso do Instituto Nacional de Ciência e Tecnologia em Democracia Digital (INCT-DD), em 2018, a título de dados preliminares, uma pesquisa com um corpus de 311 artigos, teóricos e empíricos, de revistas científicas brasileiras indexadas pelo Google Scholar. Instituições como UFBA, Universidade Federal do Paraná (UFPR), Universidade Federal de Minas Gerais (UFMG), USP, UnB, Universidade Federal Fluminense (UFF), Universidade Estadual Paulista (UNESP) e Universidade Federal de Santa Maria (UFSM), nesta ordem em termos de volume, foram aquelas com maior frequência de primeiros autores que assinam as pesquisas.

Quanto às áreas de conhecimento, a comunicação aparece como a área mais frequente (presente em $44,4 \%$ dos artigos), ou seja, em que os autores dos artigos estudados estão vinculados. Ciência política vem em segundo lugar (com 14,1\%), seguida por direito (10,9\%), sociologia $(6,4 \%)$, ciências sociais $(5,1 \%)$ e administração (4,2\%). Outros estudos também buscaram mapear as pesquisas correlatas, embora com escopo mais amplo, abarcando, por exemplo, internet e política, ou com recorte mais específico com ênfase em temas como participação ou governo eletrônico (Sampaio, Bragatto e Nicolás, 2016; Santos, Alde e Schwambach, 2016; Vianna Junior, Abreu e Batista, 2018; Przeybilovicz et al., 2015). É possível perceber que a análise de artigos empíricos publicados em periódicos científicos não foi o foco dessas pesquisas logo, a proposta deste trabalho é olhar com mais afinco nesta direção.

\section{MAPEAMENTO DA PESQUISA EMPÍRICA NO BRASIL}

Este estudo tem como foco a caracterização da produção científica sobre democracia digital publicada no Brasil em periódicos qualificados e indexados, especificamente com ênfase empírica. O procedimento metodológico e recorte foram baseados na utilização de três indexadores acadêmicos: Scientific Eletronic Library Online (Scielo), Directory of Open Access Journals (DOAJ) e Scientific Periodicals Eletronic Library (SPELL), escolhidos por serem os mais recorrentes nos periódicos brasileiros, possibilitando assim uma amostra representativa. Para acessar os artigos, foram realizadas buscas utilizando duas palavras-chave consideradas mais relevantes e comumente mencionadas por pesquisadores para definir esse campo: "democracia digital" e "democracia online" (incluindo a variação "democracia on-line"). O recorte temporal abarcou todas as publicaçóes das revistas até dezembro de 2019. Após esse processo de filtro (eliminando os casos falsos positivos), o corpus final foi composto por 73 artigos publicados em 28 revistas científicas. 
$\mathrm{Na}$ distribuição desses artigos por periódicos, detalhada na tabela 1, observa-se que oito revistas são responsáveis por mais da metade (64\%) das publicaçóes na amostra analisada: Revista de Sociologia e Política; Opiniáa Pública; Revista de Administração Pública; Revista Compolítica; Contemporânea; Intercom; Liinc em Revista; e Organizaçóes \& Sociedade.

\section{TABELA 1}

\section{Distribuição dos artigos coletados por periódico}

\begin{tabular}{|c|c|}
\hline Revista de Sociologia e Política & 11 \\
\hline Opinião Pública & 8 \\
\hline Revista de Administração Pública & 6 \\
\hline Revista Compolítica & 6 \\
\hline Contemporânea & 4 \\
\hline Intercom & 4 \\
\hline Liinc em Revista & 4 \\
\hline Organizações \& Sociedade & 4 \\
\hline Esferas & 3 \\
\hline História, Ciências, Saúde-Manguinhos & 2 \\
\hline InTexto & 2 \\
\hline Revista Debates & 2 \\
\hline e-Legis & 2 \\
\hline Ciência da Informação em Revista & 1 \\
\hline Design e Tecnologia & 1 \\
\hline Discursos Fotográficos & 1 \\
\hline Em Questão & 1 \\
\hline Galáxia & 1 \\
\hline RECIIS & 1 \\
\hline Revista Brasileira de Ciência Política & 1 \\
\hline Revista Mídia e Cotidiano & 1 \\
\hline Rizoma & 1 \\
\hline Sociologias & 1 \\
\hline e-Compós & 1 \\
\hline Cadernos de Gestão Pública & 1 \\
\hline Administração Pública e Gestão Social & 1 \\
\hline Desenvolvimento em Questão & 1 \\
\hline Revista do Serviço Público & 1 \\
\hline
\end{tabular}

Elaboração do autor.

Obs.: $\mathrm{N}=73$.

Ao colocarmos todos os artigos em linha cronológica, tomando como base o ano de publicação informado em seus metadados, traçamos um panorama dessa evolução, representado no gráfico 1. 


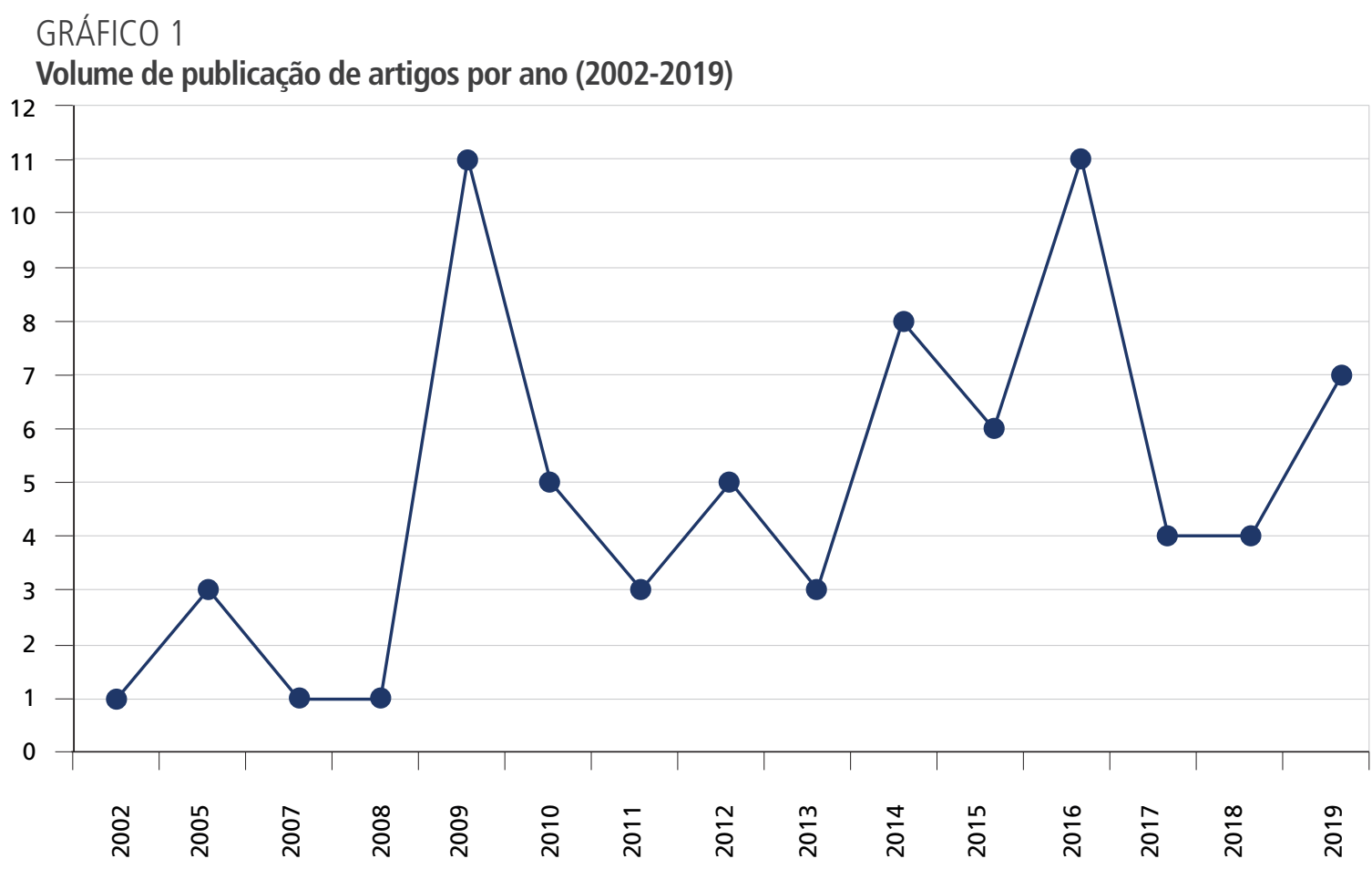

Elaboração do autor.

Obs.: 1. $N=73$.

2. Notemos que o gráfico não apresenta dados de 2003, 2004 e 2006. Por se tratar de uma amostragem, o que se pode afirmar é que a coleta de dados não captou artigos publicados nesses anos. Não podemos afirmar que não houve publicação (isso só poderia ser confirmado em uma pesquisa com o universo total dos artigos publicados). A ausência desses registros indica, sobretudo, que foram anos de baixo volume de publicação nas revistas pesquisadas, especificamente no tocante a artigos empíricos que utilizaram a expressão "Democracia Digital" como um de seus indexadores.

Observa-se que, embora não tão regular, por ser marcado por picos e depressóes, o gráfico tem uma trajetória que demonstra uma tendência ascendente. Em especial, 2009 e 2016 foram anos que demonstraram maior volume de publicação de trabalhos empíricos na amostra analisada, dado que também se alinha aos outros estudos bibliométricos citados.

Em relação às autorias, tomando como base o autor principal, o estudo demonstrou que $64,4 \%$ das publicaçóes foram vinculadas à liderança de pesquisadores do gênero masculino, contra 35,6\% de pesquisadoras do gênero feminino. Isso demonstra ainda um desequilíbrio de gênero na área no tocante ao desenvolvimento e publicação de estudos empíricos. O gráfico 2 traz um panorama da distribuição por áreas do conhecimento às quais os autores e autoras estão vinculados.

Nota-se que, quanto à vinculação institucional do primeiro autor, a área de comunicação aparece com quase metade (48\%) dos estudos empíricos sobre democracia digital, seguida de ciência política (20\%) e administração (15\%). Os autores dessas três áreas são responsáveis por cerca de 83\% dos trabalhos empíricos publicados na amostra analisada. $\mathrm{Na}$ análise por áreas de conhecimento, de acordo com a nomenclatura estipulada pela Coordenação de Aperfeiçoamento de Pessoal de Nível Superior (Capes), desta vez observando não o vínculo dos autores, e sim o vínculo das revistas, essa tendência também se confirma, conforme demonstra o gráfico 3.

Com algumas variaçóes, esses dados são convergentes com outros estudos mencionados que também detectaram a comunicação como área mais ativa, seguida por ciência política e administração (Curtinovi e Parmeggiani,2015; Sampaio et al., 2019). 


\section{GRÁFICO 2}

Distribuição dos artigos por área de vínculo dos autores/autoras (Em \%)

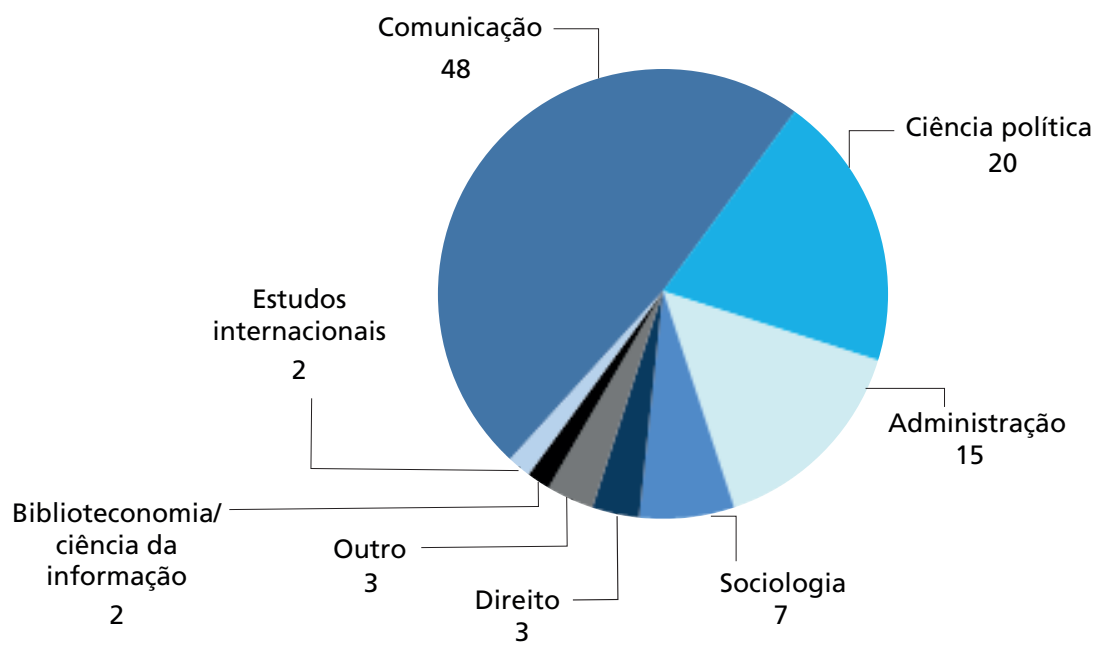

Elaboração do autor.

Obs.: $\mathrm{N}=73$

\section{GRÁFICO 3}

Distribuição dos artigos por área de vínculo dos periódicos'

(Em \%)

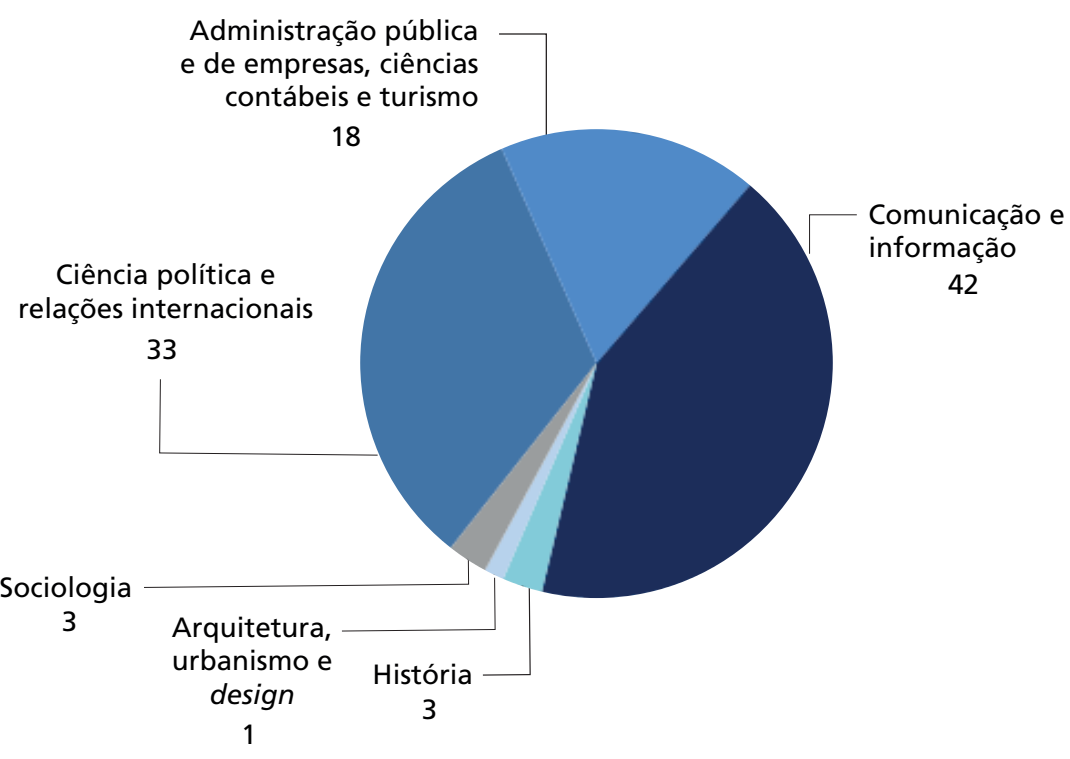

Elaboração do autor.

Nota: ${ }^{1}$ Classificação conforme nomenclaturas estipuladas pelo Qualis Capes vigente - quadriênio 2013/2016.

Obs.: $\mathrm{N}=73$.

Quanto às instituiçóes às quais os autores/autoras estão vinculados, os resultados apontam que seis universidades (todas elas públicas e federais) são responsáveis por quase metade dos trabalhos da amostra estudada, com especial destaque para a UFBA, conforme podemos visualizar na tabela 2. 
TABELA 2

Principais instituições por volume de publicação vinculadas

\begin{tabular}{lc}
\hline Nome da instituição & $\%$ \\
\hline UFBA & 16,4 \\
UFPR & 9,6 \\
UFMG & 8,2 \\
Universidade Federal do Ceará (UFC) & 6,9 \\
Universidade Federal do Maranhão (UFMA) & 4,1 \\
UFF & 4,1 \\
\hline
\end{tabular}

Elaboração do autor.

Obs.: $\mathrm{N}=73$.

Comparando com outros estudos bibliométricos, a UFBA está presente como um importante polo de publicação nesse campo (Curtinovi e Parmeggiani, 2015; Przeybilovicz et al., 2015; Sampaio et al., 2019; Pinho et al., 2019). Outras universidades aparecem em segundo plano, alternando posiçóes com alguma frequência nas cinco primeiras colocaçôes: UFPR, UnB, UFRGS, UFMG, USP e UFF. A liderança da UFBA se explica principalmente por haver, no início dos anos 2000, grupos de pesquisa trabalhando com o tema e também devido à criação do INCT.DD, que entrou em funcionamento em 2017.

Avançando agora mais especificamente no conteúdo dos artigos analisados, o estudo demonstrou que as abordagens metodológicas ${ }^{4}$ mais recorrentes foram: i) estudo exploratório, descritivo ou de mapeamento; ii) índices ou indicadores; e iii) estatísticas descritivas ou de frequência. O gráfico 4 traz uma síntese dessa dimensão.

GRÁFICO 4

Ocorrência de abordagem metodológica dos dados mencionados nos artigos ${ }^{1}$

(Em \%)

Estudo exploratório, descritivo ou mapeamento

Índices ou indicadores

Estatística descritiva ou de frequência

Estudo de caso

Análise de conteúdo

Epistemológico ou bibliométrico

Estatística inferencial

Análise de redes

Estudo de percepção ou recepção

Enquadramento

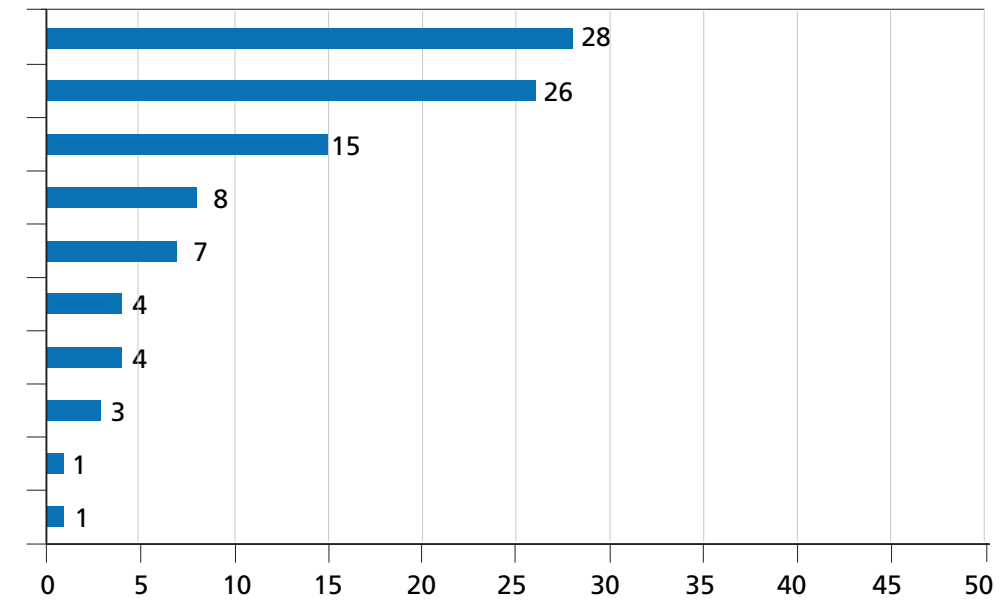

Elaboração do autor.

Nota: ${ }^{1} \mathrm{~A}$ soma das porcentagens ultrapassa $100 \%$ pois $\mathrm{N}=73$ deve ser observado isoladamente para cada uma das porcentagens das abordagens metodológicas, pois a categorização não é excludente e pode ser concomitante, ou seja, há artigos que trazem mais de uma abordagem metodológica simultaneamente.

Obs.: $\mathrm{N}=73$.

4. Foram considerados como abordagem metodológica os métodos ou instrumentos utilizados pelos artigos para analisar/interpretar os dados. 
Sobre essa dimensão metodológica, duas questóes merecem destaque. Primeiramente, é bastante comum que as pesquisas empíricas sobre democracia digital sejam estudos descritivos/exploratórios. Isso se explica devido à própria natureza inovadora dos objetos, que solicitam abordagens exploratórias e descritivas iniciais. Segundo, embora seja uma área com forte interface tecnológica, cujos objetos demandam cada vez mais o manuseio de grandes volumes de dados (oriundos de mídias sociais, por exemplo), é importante observar que o uso de estatística inferencial ainda é incipiente nesse campo, prevalecendo análises qualitativas ou quanti-quali como estatísticas de frequência ou análises descritivas.

O gráfico 5 demonstra que a coleta manual via web é preponderante nesse campo, de forma expressiva, sendo cerca de oito vezes maior que a ocorrência de artigos que trabalharam com algum software de captação ou algoritmos.

\section{GRÁFICO 5}

Ocorrências de instrumentos de coleta de dados utilizados nos artigos ${ }^{1}$ (Em \%)

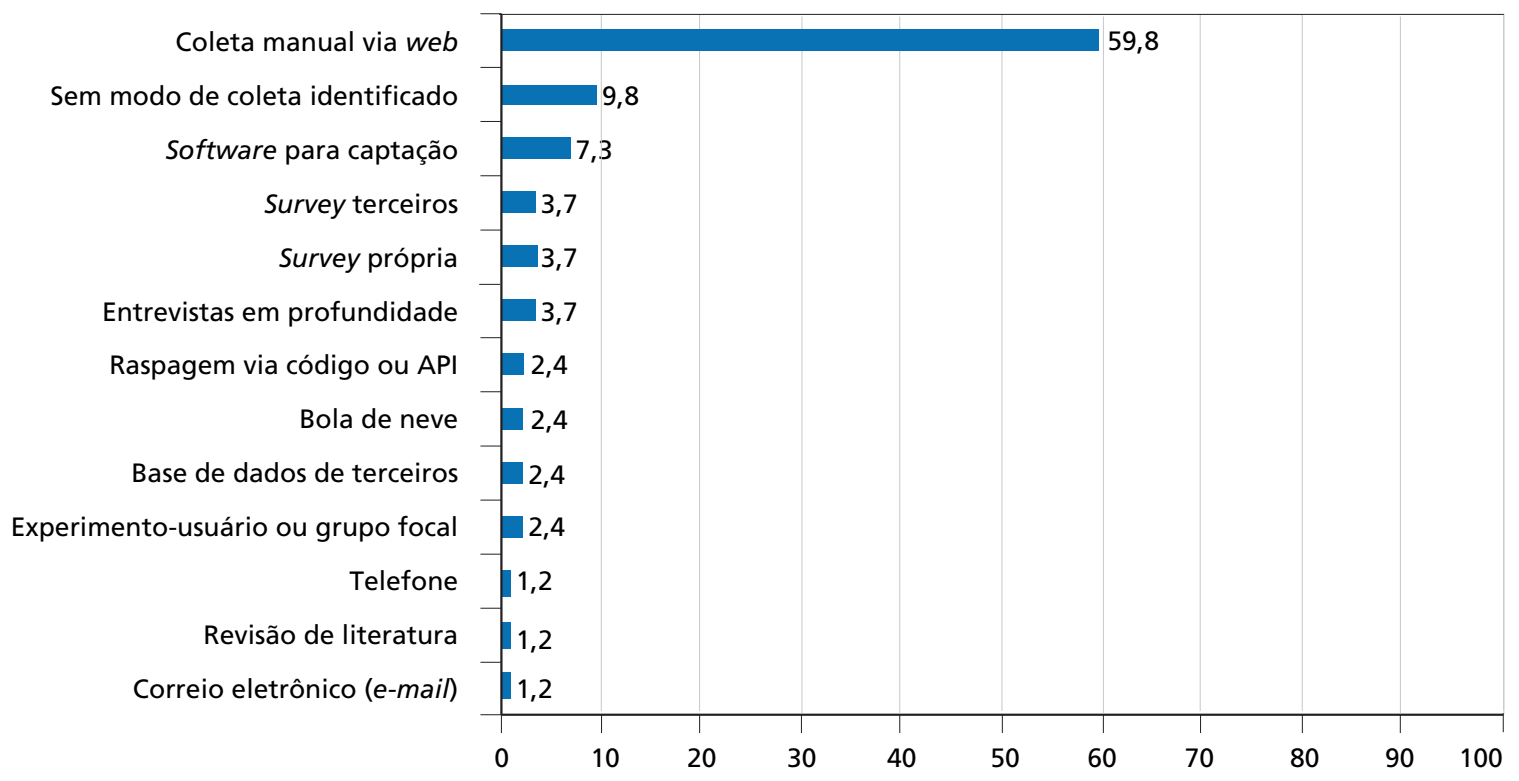

Elaboração do autor.

Nota: ${ }^{1} \mathrm{~A}$ soma das porcentagens ultrapassa $100 \%$ pois $\mathrm{N}=73$ deve ser observado isoladamente para cada uma das porcentagens das abordagens metodológicas, pois a categorização não é excludente e pode ser concomitante, ou seja, há artigos que trazem mais de uma abordagem metodológica simultaneamente.

Obs.: $1 . N=73$.

2. API - Interface de Programação de Aplicativos (Application Programming Interface).

No tocante às temáticas mais trabalhadas nos artigos, o gráfico 6 demonstra que participação ou engajamento político é responsável por um terço (quase 34\%) da amostra. Deliberação/conversação on-line (18\%), campanhas eleitorais $(16,9 \%)$ e parlamento digital $(9,6 \%)$ aparecem em seguida como temas mais abordados.

Esses dados também corroboram as análises internacionais sobre a pesquisa em democracia digital apontando temas como participação, deliberação e campanhas on-line como aqueles mais recorrentes (Gomes, 2016). Isso demonstra que o Brasil acompanha uma tendência mundial. 


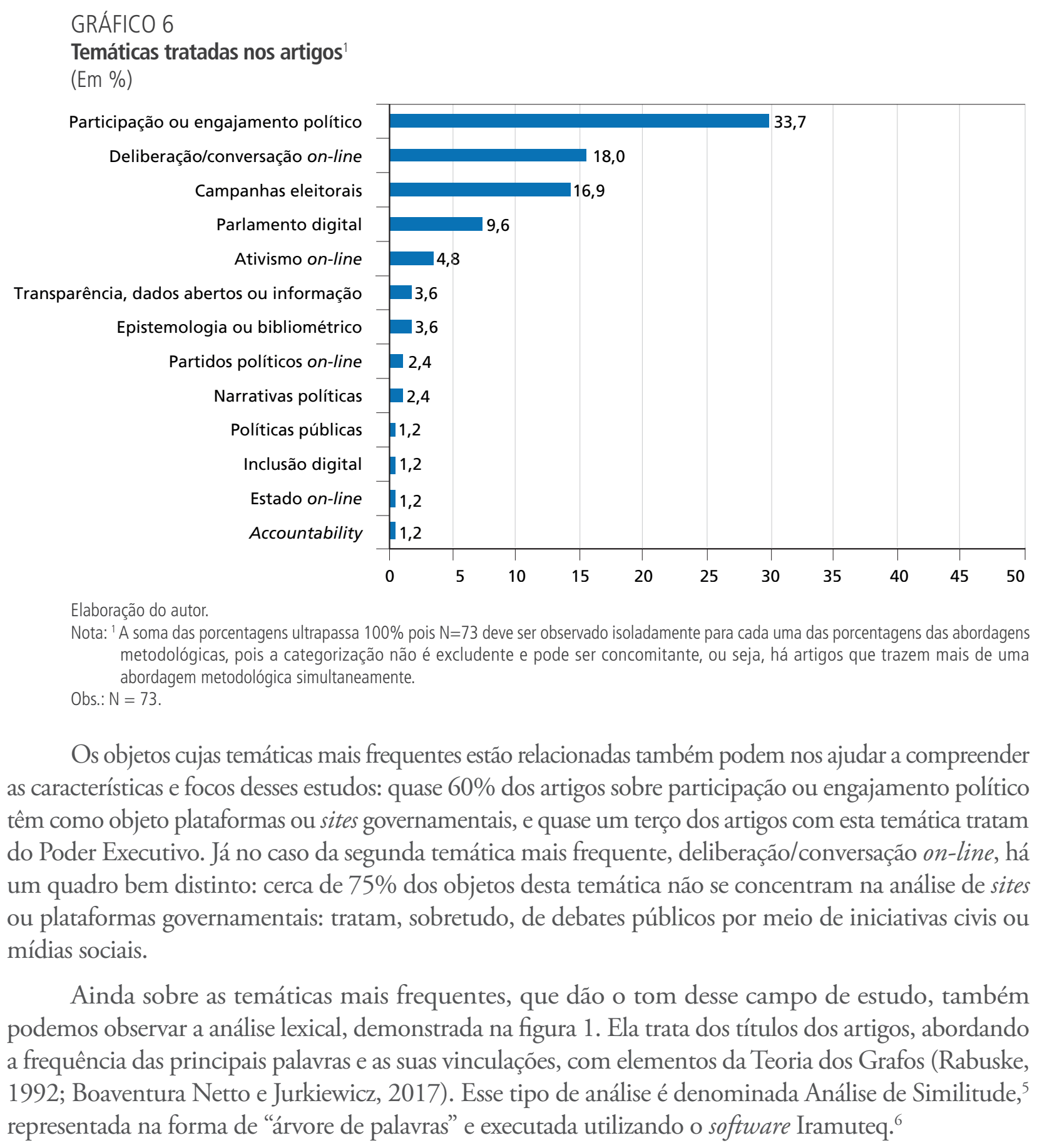

GRAFICO 6

Temáticas tratadas nos artigos

Participação ou engajamento político

(iberaçao/conversação on-line

Campanhas eleitorais

rlamento digital 


\section{FIGURA 1}

Análise de similitude sobre os títulos dos artigos

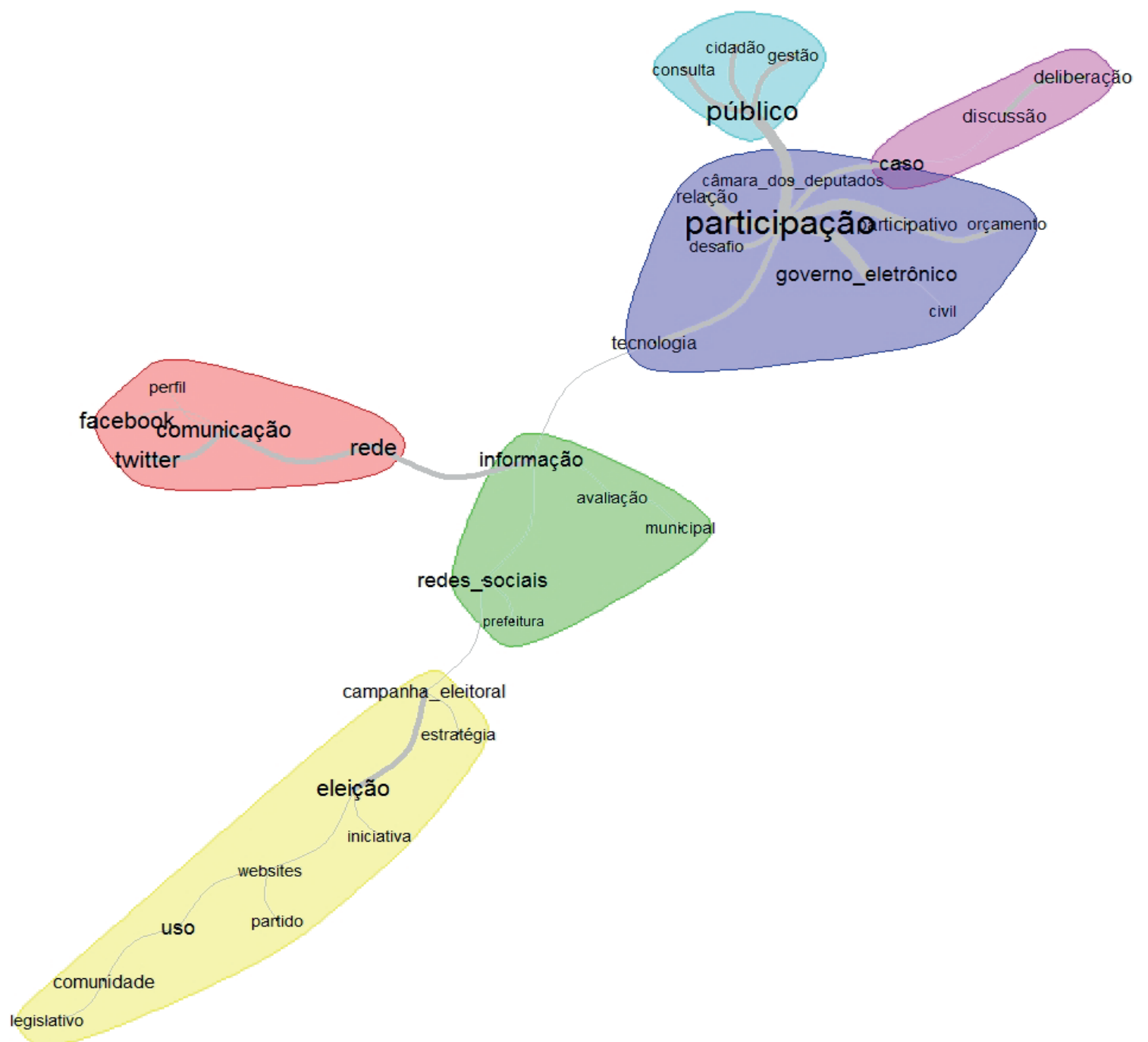

Elaboração do autor.

Obs.: 1. Foi utilizado o software Iramuteq para a elaboração desta figura.

2. Figura cujos leiaute e textos não puderam ser padronizados e revisados em virtude das condições técnicas dos originais (nota do Editorial).

A partir do resultado dessa análise (figura 1) podemos identificar os termos mais relevantes ${ }^{7}$ quanto a ênfases lexicais-semânticas que aparecem nos artigos empíricos sobre democracia digital no Brasil, formando clusters em termos lexicais.

1) Primeiramente, há de se notar o destaque do cluster participação, que é um dos mais importantes e demonstra o quanto esse tema é frequente nos artigos e como possui fortes ligaçóes com outros clusters. Isso pode ser visto na espessura dos grafos entre os clusters.

7. Tais considerações se baseiam na observação dos clusters (palavras próximas e mais frequentes, que foram "ilhas" na Árvore de Palavras) e grafos (ligamentos entre os clusters, que seriam os "galhos" que conectam as "ilhas"). 
2) Uma segunda ilha lexical que também merece destaque é o cluster comunicação, que reflete a importância da comunicação enquanto área de conhecimento bastante ativa nesse campo e o vínculo disso com a análise de redes sociais (Facebook, Twitter etc.).

3) Um terceiro cluster em destaque gira em torno da palavra eleição, que demonstra a presença de estudos sobre campanhas eleitorais, partidos e público, formando nós relevantes. $\mathrm{O}$ termo informação também demonstra forte relação de grafos com o cluster comunicação.

4) O cluster público aparece como um conjunto semântico sempre muito vinculado a experimentos e experiências de gestão pública; consultas públicas; e público e cidadão, com forte vínculo com o cluster participaçáo, o que demonstra o caráter público das temáticas participativas.

5) Por fim, o cluster deliberação também aparece em destaque, se referindo principalmente à presença dos estudos sobre deliberação on-line; esfera púbica digital; e democracia deliberativa e internet, também com fortes ligaçóes (grafos) ao cluster participação.

Cerca de 16,4\% dos artigos declararam utilizar algum tipo de software (seja para captação ou análise) ou linguagem de programação. Os mais mencionados foram: Selenium, SPSS, UCINET, NetDraw, Excel, Nvivo, Netvizz, HTTrack Website Copier, Netlytic, Iramuteq, R(studio), Atlas T.I. e Python. Cerca 58,3\% dos software citados são gratuitos ou open source; $25 \%$ software proprietários e $16,7 \%$ são dúbios quanto a esta característica.

As abordagens temáticas que mais utilizaram software/scripts foram estudos que tratavam de campanhas eleitorais; epistemologia ou bibliométrico; e parlamento digital, que, somados, representam cerca de $67 \%$ das pesquisas que utilizaram algum tipo de software/script. O objeto que mais utilizou softwares/ scripts foi mídias sociais, presente em quase $60 \%$ dos artigos que lançaram mão de algum software/script. Em segundo lugar, aparecem objetos do tipo produção científica/acadêmica, com cerca de $17 \%$ dos artigos que utilizaram software/script.

\section{CONSIDERAÇÕES FINAIS}

Este trabalho teve como objetivo produzir um levantamento do atual estágio da pesquisa sobre democracia digital, com foco nos estudos de caráter prático e empírico, especificamente em periódicos científicos brasileiros em três importantes indexadores.

Em linhas gerais, os resultados apontaram que os 73 artigos analisados na amostra estavam distribuídos em 28 revistas científicas de diversas áreas do conhecimento. Isso demonstra e confirma a multidisciplinaridade desse campo, o qual perpassa periódicos de diferentes escopos de estudo. Ao mesmo tempo, os dados também corroboram outros estudos bibliométricos que apontam para protagonismo de áreas como comunicação, ciência política e administração como grandes produtoras de conhecimento.

Embora ainda oscilantes, os dados também demonstraram que a pesquisa empírica está em linha ascendente. Observou-se que o período entre 2009 e 2011 significou um aumento expressivo do volume de estudos empíricos nesse campo, e, partir de 2011, percebe-se que há uma tendência de crescimento, apesar de uma pequena queda em 2017 e 2018, mas já apontando retomada ascendente em 2019.

Também ficou evidente que o campo é marcado por um volume substancial de estudos exploratórios ou descritivos, com ocorrências significativas do uso de indicadores ou estatísticas tanto descritivas quanto de frequência, como abordagens metodológicas proporcionalmente mais recorrentes. Plataformas ou sites governamentais e mídias sociais têm sido os objetos mais recorrentes nos estudos empíricos sobre democracia digital. 
Embora os objetos de estudo dessa área sejam especificamente digitais, a coleta de dados ainda é manual e faz um baixo uso de software, algoritmos ou outros instrumentos de coleta de dados, sendo as análises sobre mídias sociais as que mais os utilizam. Embora a porcentagem seja relativamente baixa (cerca de $16 \%$ dos artigos utilizam softwares/script), esse tipo de instrumento tende a aumentar, haja vista o crescimento do volume de dados digitais a serem analisados nesse campo e o próprio movimento de formação de pesquisadores em instrumentos digitais de coleta e análise desse ascendente volume de informaçóes.

Os dados trazem um panorama do atual estágio da pesquisa empírica desse campo, que é relativamente novo. Outros estudos futuros podem ser interessantes para se avaliar longitudinalmente como isso irá evoluir e que tipo de caminhos empíricos-metodológicos o campo da democracia digital tende a seguir em termos de métodos, instrumentos e análises. Sobretudo, é preciso compreender que a própria noção de democracia está inevitavelmente conectada à dinâmica das mudanças oriundas dos processos e fenômenos digitais. Portanto, o desenvolvimento de pesquisas sobre democracia digital nada mais é que o próprio reflexo da evolução do debate histórico sobre teorias e práticas democráticas, dessa vez no contexto e realidade do século XXI.

Por fim, de modo mais especulativo, também podemos vislumbrar que há uma tendência das pesquisas da área para uma aproximação cada vez maior de métodos vinculados a ciência de dados e uso de algoritmos para coleta e processamento de informaçóes. Isso se dá pela congruência da própria natureza dos objetos digitais e pelo grande volume de informação que as práticas e instituiçôes democráticas tendem a produzir. Isso requer que o perfil do pesquisador esteja adequado para dar conta dessa dimensão cada vez mais complexa, o que implica também em uma mudança nos processos de formaçáo.

\section{REFERÊNCIAS}

BOAVENTURA NETTO, P. O.; JURKIEWICZ, S. Grafos: introdução e prática. São Paulo: Blucher, 2017. CURTINOVI, J.; PARMEGGIANI, B. Investigações sobre democracia digital no Brasil: um mapeamento da produção acadêmica até 2013. Revista Comunicando, n. 4, p. 99-116, 2015.

FREITAS, C. et al. Análise da rede de produção de conhecimento sobre a iniciativa e-Democracia. In: CONGRESSO DO INCT.DD, 1., 2018, Salvador. Anais ... Salvador: INCD.DD, 2018.

GOMES, W. Participação política on-line: questóes e hipóteses de trabalho. In: MAIA, R. C. M.; GOMES, W.; MARQUES, F. P. J. A. (Org.). Internet e participação política no Brasil. Porto Alegre: Sulina, 2011. p. 19-45.

. 20 anos de política, Estado e democracia digitais: uma cartografia do campo. In: SILVA, S.; BRAGATTO, R.; SAMPAIO, R. (Org.). Democracia digital, comunicaçáo política e redes: teoria e prática. Rio de Janeiro: Letra \& Imagem, 2016. p. 39-76.

MEDAGLIA, R. eParticipation research: moving characterization forward (2006-2011). Government Information Quarterly, n. 29, p. 346-360, 2012.

PINHO, J. A. G. et al. Democracia digital na área de administração: um levantamento da construçáo do campo no Brasil. Cadernos Gestáo Pública e Cidadania, n. 24, ed. 78, p. 1-31, 2019. 
PRZEYBILOVICZ, E. et al. O desenvolvimento dos estudos sobre governo eletrônico no Brasil: um estudo bibliométrico e sociométrico. Revista Eletrônica de Sistemas de Informaçáo, n. 14, v. 3, 2015. RABUSKE, M. Introdução à teoria dos grafos. Florianópolis: UFSC, 1992.

SAMPAIO, R. C.; BRAGATTO, R. C.; NICOLÁS, M. A. A construção do campo de internet e política: análise dos artigos brasileiros apresentados entre 2000 e 2014. Revista Brasileira de Ciência Política, n. 4, p. 285-320, 2016.

SANTOS, J. G. B.; ALDE, A.; SCHWAMBACH, A. C. F. Panorama das teses e dissertaçóes brasileiras envolvendo Internet e Política de 1995 a 2014. In: ENCONTRO ANUAL DA ANPOCS, 40., 2016, Caxambu. Anais.... Caxambu: ANPOCS, 2016.

SILVA, S. P. da; SAMPAIO, R. C.; BRAGATTO, R. C. Concepçóes, debates e desafios da democracia digital. In: SILVA, S. P. da; BRAGATTO, R. C.; CARDOSO, R. C. S. (Org.). Democracia digital, comunicaçáo política e redes. 1. ed. Rio de Janeiro: Folio Digital, 2016. p. 17-38.

VIANNA JUNIOR, A. J. de O.; ABREU, J. C. A. de; BATISTA, W. J. Democracia digital e participação cidadã. Org \& Demo, n. 19, v. 2, p. 49-62, 2018. 